\title{
Plausible antioxidant biomechanics and anticonvulsant pharmacological activity of brain-targeted $\beta$-carotene nanoparticles
}

This article was published in the following Dove Press journal:

International Journal of Nanomedicine

3 August 2012

Number of times this article has been viewed

\author{
Mohammad Yusuf' \\ Riaz A Khan ${ }^{3}$ \\ Maria Khan ${ }^{2}$ \\ Bahar Ahmed' \\ 'Department of Pharmaceutical \\ Chemistry, ${ }^{2}$ Department of \\ Pharmacognosy and Phytochemistry, \\ Faculty of Pharmacy, Hamdard \\ University, New Delhi, India; \\ ${ }^{3}$ Department of Chemistry, Manav \\ Rachna International University, \\ National Capital Region, Aravali Hills, \\ Faridabad, India
}

\begin{abstract}
Carotene has been established as a known free radical scavenger with chainbreaking antioxidant properties. It has been documented for the treatment of epileptic convulsions at a $200 \mathrm{mg} / \mathrm{kg}$ body weight dose. The reported pathogenesis for epileptic convulsions is oxidative stress. Hence, experimental epileptic convulsions via oxidative stress was induced in albino mice epileptic models (maximal electroshock seizure and pentylenetetrazole [PTZ]). A dose concentration equivalent to $2 \mathrm{mg} / \mathrm{kg}$ was efficaciously administered in the form of brain-targeted polysorbate-80-coated poly(d,1-lactide-co-glycolide) nanoparticles. The nanoparticles were prepared by solvent evaporation technique and further characterized for their physical parameters, in-vitro release kinetics, and in-vivo brain release via various standard methods. Normal $\beta$-carotene nanoparticles (BCNP) and polysorbate- 80 -coated $\beta$-carotene nanoparticles (P-80-BCNP) of $169.8 \pm 4.8 \mathrm{~nm}$ and $176.3 \pm 3.2 \mathrm{~nm}$ in size, respectively, were formulated and characterized. Their zeta potential and polydispersity index were subsequently evaluated after 5 months of storage to confirm stability. In vivo activity results showed that a $2 \mathrm{mg}$ unformulated $\beta$-carotene dose was ineffective as an anticonvulsant. However, salutary response was reported from BCNP at the same dose, as the hind limb duration decreased significantly in maximal electroshock seizure to $9.30 \pm 0.86$ seconds, which further decreased with polysorbate- 80 coating to $2.10 \pm 1.16$ seconds as compared to normal control (15.8 \pm 1.49 seconds) and placebo control (16.50 \pm 1.43 seconds). In the PTZ model, the duration of general tonic-clonic seizures reduced significantly to $2.90 \pm 0.98$ seconds by the use of BCNP and was further reduced on P-80-BCNP to $1.20 \pm 0.20$ seconds as compared to PTZ control and PTZ-placebo control (8.09 \pm 0.26 seconds). General tonic-clonic seizures latency was increased significantly to $191.0 \pm 9.80$ seconds in BCNP and was further increased in P-80-BCNP to $231.0 \pm 16.30$ seconds, as compared to PTZ (120.10 \pm 4.50 seconds) and placebo control (120.30 \pm 7.4 seconds). The results of this study demonstrate a plausible novel anticonvulsant activity of $\beta$-carotene at a low dose of $2 \mathrm{mg} / \mathrm{kg}$, with brain-targeted nanodelivery, thus increasing its bioavailability and stability.
\end{abstract}

Keywords: anticonvulsant, blood-brain barrier (BBB), targeted brain delivery, polysorbate80 -coated $\beta$-carotene nanoparticles (P-80-BCNP), maximal electroshock seizure (MES), pentylenetetrazole (PTZ)

\section{Introduction}

Epilepsy debilitates more than 50 million people worldwide. ${ }^{1}$ The majority of the affected population suffers from generalized tonic-clonic seizures, while others are affected with multiple forms of the disorder. One of the main pathogenesis of epilepsy is oxidative stress wherein the brain utilizes high amounts of oxygen as compared to other body organs. This consequently results in cellular disruptions, damage, and 
eventual cell death. ${ }^{2}$ The consequences of oxidative stress are due to the oxidation of functional biomolecules such as proteins, lipids, and nucleotides in various cells. ${ }^{3}$ Protein oxidation leads to the deactivation of several enzyme systems and their associated functional changes, while lipid peroxidation causes membrane structure alterations resulting in changes in membrane fluidity, permeation, and biological functionality. ${ }^{4,5}$

An increased calcium ion concentration in neuronal tissue leads to a cascade of biochemical responses which trigger neuronal cell death after status epilepticus. ${ }^{6}$ High levels of intracellular calcium ions induce reactive oxygen species (ROS) in a biosystem mainly through xanthine oxidase and nicotinamide adenine dinucleotide phosphate oxidase mediated biochemical reactions..$^{7-9}$ The increased level of superoxide radicals result in an equally elevated hydrogen peroxide level via a superoxide dismutase mediated reaction. Highly reactive hydroxyl $(\mathrm{OH})$ free radicals generated by the reaction of peroxynitrite with superoxide radicals, ${ }^{10}$ or through Fenton reactions, ${ }^{11}$ readily oxidize the structural proteins of the cell membrane resulting in the disruption of cellular membrane fluidity, permeation, and overall biological functionality including that of the neuronal cells, DNA, and lipids. ${ }^{9}, 12$ Physiological levels of ROS are maintained by means of scavenging through enzymatic (eg, superoxide dismutase, catalase, glutathione peroxidase, glutathione reductase, and peroxiredoxins) and nonenzymatic reactions of antioxidants. ${ }^{3,14-16}$

Many biological experiments conducted by use of kainic acid, iron-salt, and electroshock induced seizures, as well as the kindling model by pentylenetetrazole (PTZ) have confirmed the relation of ROS and other species with convulsions. ${ }^{17-21} \mathrm{PTZ}$, an epilepsy inducing agent, is a selective blocker of $\mathrm{GABA}_{\mathrm{A}}$ receptor-chloride ionophore complex, which induces convulsions by triggering the glutamatergic transmitter system. This activation is due to an increased intracellular calcium ion influx, which results in an increased production of superoxide radicals $\left(\mathrm{O}_{2}{ }^{-}\right)$(Figure 1)..$^{22,23}$ The well-standardized and validated PTZ-induced model was selected for the present study. ${ }^{24}$

$\beta$-Carotene, a known source of vitamin A, has exceptional antioxidant and free radical scavenging potential. ${ }^{25,26}$ Its antiepileptogenic activity has been established in PTZinduced epilepsy models. ${ }^{27}$ Earlier work provided evidence that $\beta$-carotene-enriched feeding of adult rats for a 1-week trial delayed the onset of induced seizures. ${ }^{28} \beta$-Carotene is converted into retinol in the biosystem, and due to its antioxidant activity, it plays an important role in preventing

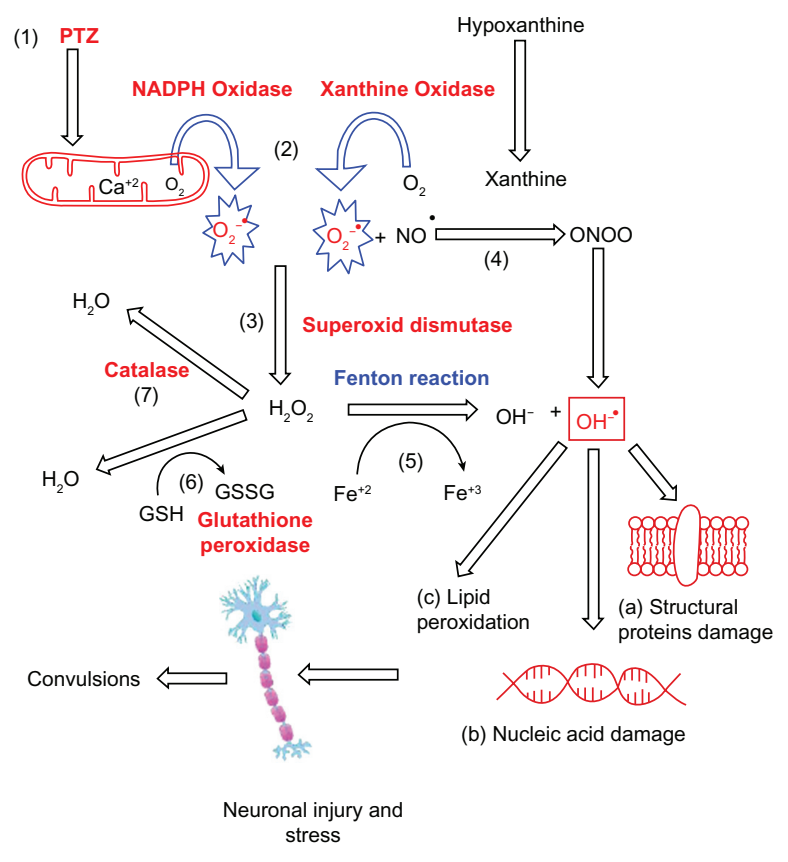

Figure I Mechanism of free radical generation.

Notes: (I) Pentylenetetrazole kindling activates the glutamatergic transmitter system which increases the intracellular calcium ion concentration and induces the formation of $\mathrm{O}_{2}$. (2) Xanthine oxidase and nicotinamide adenine dinucleotide phosphate oxidase generates the superoxide radical, $\mathrm{O}_{2}{ }^{-}$and has been widely applied as a $\mathrm{O}_{2}{ }^{-}$-generating system. (3) Increased hydrogen peroxide production through the catalyzed dismutation of $\mathrm{O}_{2}$ - by superoxide dismutase. (4) Production of $\mathrm{ONOO}^{-}$from $\mathrm{NO}$ and superoxide radical, which further produces $\mathrm{OH}^{-}$- free radical. (5) Production of $\mathrm{OH}^{-}$free radical through Fenton reaction, readily oxidizes structural proteins of the Neuronal cells thus disrupting their fluidity, permeation and biological functioning (a) DNA (b) and lipids (c). (6) The enzyme glutathione peroxidase utilizes reduced glutathione to eliminate hydrogen peroxide as $\mathrm{H}_{2} \mathrm{O}$. (7) Hydrogen peroxide is broken down into water and oxygen by the enzyme catalase. Abbreviations: $\mathrm{NADPH}$, nicotinamide adenine dinucleotide phosphate; $\mathrm{O}_{2}{ }^{-}$, superoxide radical; $\mathrm{ONOO}^{-}$, peroxynitrite; $\mathrm{NO}$, nitric oxide; $\mathrm{OH}^{-}$, highly reactive hydroxyl; DNA, Deoxyribonucleic acid.

neurodegenerative disorders. ${ }^{29}$ The high hydrophobicity of $\beta$-carotene makes it insoluble in an aqueous medium and thus restricts its absorption through the diet. Previous studies have focused on improving the dispersibility of carotenoids in water so as to increase its bioavailability. ${ }^{30}$ Some researchers have developed water-dispersible formulations as carriers to entrap carotenoids and direct them to in vitro and in vivo systems. ${ }^{31-34}$ The polymer-based delivery system consisting of nanoscale carriers provides an alternative mode of carotenoid delivery. These formulations have shown increased physiochemical stability of the encapsulated $\beta$-carotene. ${ }^{35,36}$ The polyester poly(d,1-lactide-co-glycolide) (PLGA) nanoparticles were selected due to their biocompatibility, biodegradation properties, US Food and Drug Administration approval for biological use, successful central nervous system delivery, and its facile biodecomposition without being immunogenic or prone to producing inflammation at the site of action. ${ }^{37,38}$ 
Our objective was to focus on reducing the central nervous system's oxidative stress with the use of known and natural antioxidants like $\beta$-carotene. The antioxidants were delivered to specific sites of disorder across the blood-brain barrier in neuronal tissues, which were then believed to control epilepsy through a free radical scavenging mechanism. However, drug targeting to neuronal regions require its delivery to be strictly localized, including its pharmacological active manifestation to the particular brain site. Polysorbate80 -coated $\beta$-carotene nanoparticles (P-80-BCNP) appeared to follow a similar required course of delivery in mimicking the adsorption of low-density lipoprotein, apolipoprotein-E, and apolipoprotein-A1 after their injection into the systemic blood circulation followed by receptor-mediated endocytosis of the nanoparticles by the brain barrier's capillary endothelial cells. ${ }^{39,40}$ This hypothesis by Kreuter and Kim was supported by the fact that covalent coupling of apolipoprotein-E and apolipoprotein-A1 to human serum albumin nanoparticles lead to similar endocytosis. ${ }^{41-43}$ In the present study, polysorbate- 80 was used as the coating surfactant for intended $\beta$-carotene-loaded nanoparticles for its brainspecific delivery. Hence, P-80-BCNP were prepared and anticonvulsant activity was evaluated with the intent to: (1) improve bioavailability at the site of action; (2) increase the stability of $\beta$-carotene in nanoparticle formulations; and (3) target required quantities of $\beta$-carotene to the brain site in reduced doses. To date, there has been no known documentation on the nanomodulated delivery of $\beta$-carotene to the brain with anticonvulsant activity.

\section{Materials and methods Procurement of raw materials}

$\beta$-Carotene, PLA $\mathrm{M}_{\mathrm{w}}$ 31,000-50,000, PLGA M $\mathrm{w}$ 4,00015,000 , and hydrophobic polytetrafluoroethylene filters (pore diameter $0.5 \mathrm{~mm}$ ) were purchased from Sigma-Aldrich (Milwaukee, WI). High-pressure liquid chromatography (HPLC)-grade acetone and Tween-80 (polysorbate-80) were purchased from SD Fine Chemicals (Mumbai, India). All materials were used as obtained.

\section{Preparation of nanoparticles}

Polymeric nanoparticles containing $\beta$-carotene at variable concentrations of polymers were prepared using a solvent displacement technique at room temperature $\left(25^{\circ} \mathrm{C}\right)$. Briefly, in a typical preparation procedure providing the greatest entrapment of the drug, $10.0 \mathrm{mg}$ of $\beta$-carotene was dissolved in $30.0 \mathrm{~mL}$ of acetone, followed by dissolution of $2.00 \mathrm{mg}$ of $\alpha$-tocopherol (as stabilizer), and $100.0 \mathrm{mg}$
PLGA with $45.0 \mathrm{mg}$ of PVA. The resulting solution was then gradually, in a drop-by-drop manner, added to a $30.0 \mathrm{~mL}$ aqueous phase containing 1\% Tween-80 (as a dispersing agent) with continuous stirring at $10,000 \mathrm{rpm}$ for 20 minutes. Following the addition, $70.0 \mathrm{~mL}$ of water was then added, and the organic solvent was allowed to diffuse into the aqueous phase. Acetone was eliminated by using a rotary vacuum evaporator under controlled temperature $\left(<40^{\circ} \mathrm{C}\right)$ and vacuum. The resultant volume was further concentrated to one fifth of the original volume under the same conditions to give approximately $30.0 \mathrm{~mL}$ of final volume, which was subsequently freeze-dried and stored in a sealed dark amber vial at $-4.0^{\circ} \mathrm{C} \pm 2.0^{\circ} \mathrm{C}$ to produce $\mathrm{BCNP}$. The lyophilized nanoparticles (BCNP) were reconstituted in double distilled water and were further coated by stirring in $1 \%$ polysorbate- 80 (Tween-80) for 1 hour to produce $\mathrm{P}-80$-BCNP.

\section{Entrapment efficiency}

$\beta$-carotene was extracted from nanoparticles by dissolving it in $2.0 \mathrm{~mL}$ ethanol and $3.0 \mathrm{~mL}$-hexane. The mixture was shaken, and the hexane phase was then recovered. The extraction was repeated twice and the recovered hexane phase was then further diluted with the same to $25 \mathrm{~mL}$ quantity sufficient. Absorbance was measured at a $450 \mathrm{~nm}$ wavelength using a Shimadzu UV-spectrophotometer (UV 1601; Shimadzu, Tokyo, Japan $)^{44}$ by means of a standard curve ranging from $1-10 \mu \mathrm{g} / \mathrm{mL}\left(\mathrm{r}^{2}=0.99\right)$. The percent entrapment efficiency was represented as follows:

$$
\% \mathrm{EE}=\frac{[\mathrm{W}(\text { initial })-\mathrm{W}(\text { free drug })]}{\mathrm{W}(\text { initial })} \times 100
$$

W(initial) represents the drug taken in nanoparticle form for assay, and W(free drug) represents the free drug present in the supernatant.

\section{Distribution and nanoparticle size}

Particle size, zeta potential, and polydispersity index was determined by Zetasizer (Malvern Instruments, Worcestershire, UK). For long-term stability testing, particle size measurements were conducted over a 5 -month storage period and frozen at $-4^{\circ} \mathrm{C} \pm 2^{\circ} \mathrm{C}$.

\section{Transmission electron microscopy (TEM)} Morphology of nanoparticles was analyzed using TEM (Morgagni 268D; SEI, Collegeville, PA). Briefly, a drop of sample was placed onto a 300-mesh copper grid and 
rested for 1 minute, followed by the addition of a drop of phosphotungstic acid and left again for 10 seconds. Residual phosphotungstic acid was removed by absorption, and the sample was analyzed at $60-80 \mathrm{KV}$ at $1550 \times$ magnification.

\section{$\mathrm{X}$-ray diffractometer studies}

An X-ray diffractometer (PW 1830; Phillips, Bangalore, Karnataka, India) was used. Samples were exposed to monochromatic $\mathrm{Cu} \mathrm{K}$ - radiation $(0.45 \mathrm{kV} \times 20 \mathrm{~mA}$, $\lambda=1.5406 \AA$ ) obtained by Ni filtration, and a system of $\mathrm{D} / \mathrm{R} / \mathrm{S}$ slides of $1^{\circ}, 0.2 \mathrm{~mm}$, and $1^{\circ}$, respectively. The diffraction pattern was determined in the area $10^{\circ}<2 \theta<60^{\circ}$, using a stepwise method $\left(0.2^{\circ} / \mathrm{s}\right)$.

\section{Differential scanning calorimetric (DSC) studies}

DSC experiments were carried out (TA Instruments, Brussels, Belgium) to determine the possible interactions between the drug and polymer. Briefly, between 5.0 to $10.0 \mathrm{mg}$ of polyvinyl alcohol (PVA), PLGA, $\beta$-carotene, and lyophilized nanosuspension samples were added into aluminum pans, which were hermetically sealed. The heating rate was kept constant at $5^{\circ} \mathrm{C} / \mathrm{min}$, while nitrogen served as a purge gas to control the temperature of the system.

\section{Animals}

Male albino mice (25.0-30.0 gm weight) were received from Animal House after clearance from the institutional ethics committee (173/Committee for the Purpose of Control and Supervision on Experiments on Animals, Tamil Nadu, India). The animals were housed in colony cages under ambient temperature $\left(25.0^{\circ} \mathrm{C} \pm 2.0^{\circ} \mathrm{C}\right)$ with a $45 \%-55 \%$ relative humidity and under 10 -hour light/14-hour dark cycles. The animals were allowed food and water ad libitum.

\section{Dosing}

Six groups of six animals each were taken for the maximal electroshock seizure (MES) study. Group 1 received 5\% carboxymethylcellulose (CMC) as a normal control; Group 2 received $\beta$-carotene (200 mg/kg, 5\% CMC); Group 3 received $\beta$-carotene ( $2 \mathrm{mg} / \mathrm{kg}, 5 \% \mathrm{CMC}$ ); Group 4 received placebo nanoparticles in 5\% CMC as a placebo control; Group 5 received BCNP (2 mg/kg $\beta$-carotene, 5\% CMC); and Group 6 received P-80-BCNP in $2 \mathrm{mg} / \mathrm{kg} \beta$-carotene, $5 \%$ $\mathrm{CMC}$. An apparatus with ear electrodes was used to deliver the stimuli. ${ }^{45}$ The intensity of stimulus was $12 \mathrm{~mA}, 50 \mathrm{~Hz}$ for 0.2 seconds, wherein hind limb muscle extensor was the evaluation parameter.

In the PTZ kindling method, for the evaluation of general tonic-clonic seizure duration and latency, two sets of seven groups with six animals per group were taken. Group 1 was given 5\% CMC as normal control; Group 2 received PTZ (60 mg/kg) as PTZ-control; Group 3 received PTZ (60 mg/kg) + $\beta$-carotene ( $2 \mathrm{mg} / \mathrm{kg}, 5 \% \mathrm{CMC})$; Group 4 received PTZ $(60 \mathrm{mg} / \mathrm{kg})+\beta$-carotene $(200 \mathrm{mg} / \mathrm{kg}, 5 \%$ CMC); Group 5 received PTZ $(60 \mathrm{mg} / \mathrm{kg})+$ placebo nanoparticles in 5\% CMC as a placebo control; Group 6 received PTZ (60 mg/kg) + BCNP (2 mg/kg $\beta$-carotene, 5\% CMC); and Group 7 animals received PTZ (60 mg/kg) + P-80-BCNP ( $2 \mathrm{mg} / \mathrm{kg} \beta$-carotene, 5\% CMC). All animals were observed for a period of 30 minutes after PTZ administration, and the duration and latency of general tonic-clonic seizure were evaluated as parameters. ${ }^{46}$ Dose response studies ranged from a start of $200 \mathrm{mg} / \mathrm{kg}$ down to $2 \mathrm{mg} / \mathrm{kg}$, and the dose fraction study was performed separately for the various antioxidants (Piperine, Capsaicin, Curcumin, $\beta$-carotene) (data are not shown). All the doses were administered via an intraperitoneal route.

\section{In vitro $\beta$-carotene release}

The release of $\beta$-carotene from nanoformulations were carried out in phosphate buffer saline (PBS, $154 \mathrm{mM}, \mathrm{pH} 7.4$ ) containing $1 \% \mathrm{w} / \mathrm{v}$ Tween -80 at $37^{\circ} \mathrm{C}, 100 \mathrm{rpm}$ in an orbital shaker (Barnstead Lab-Line, USA). Two milligram equivalent nanoparticle formulations were dispersed in $2.0 \mathrm{~mL}$ PBS and transferred into a dialysis bag (SigmaAldrich, cut off size $10 \mathrm{kDa}$ ), which was immersed into a $50.0 \mathrm{~mL}$ falcon tube containing $5.0 \mathrm{~mL}$ of PBS and ethyl alcohol $(50.0 \% \mathrm{v} / \mathrm{v})$. At predetermined intervals, all buffer solutions in the falcon tube were removed and replaced with a fresh solution. The $\beta$-carotene concentrations in the released samples were determined using a UV/VIS spectrophotometer using standard samples of $\beta$-carotene $(0-10 \mu \mathrm{g} / \mathrm{mL})$.

\section{Release of $\beta$-carotene in brain}

HPLC (Shimadzu, Japan) coupled with a UV/VIS detector (200 IC, USA), $\mathrm{C}_{18}$ column $(4.6 \mathrm{~mm} \times 250 \mathrm{~mm}, 5 \mu \mathrm{m}$, Theale Reading, Berks, UK), loaded with DataApex Clarity Lite (DataApex Ltd, Prague, Czech Republic) software was employed for all quantitative analyses. A mobile phase consisting of $1: 1(\mathrm{v} / \mathrm{w})$ of acetonitrile in $0.01 \mathrm{M} \mathrm{KH}_{2} \mathrm{PO}_{4}$ adjusted to a $\mathrm{pH} 4.5$ using orthophosphoric acid was used 
at a flow rate of $1.00 \mathrm{~mL} / \mathrm{min}$ with detections assessed at $450 \mathrm{~nm}$. $\beta$-carotene standards were freshly-prepared by diluting a stock solution in the above mentioned mobile phase to a concentration range of $2-100 \mathrm{ng} / \mathrm{mL}$. The standards showed good linear correlation and accuracy with an average percentage curve value of less than $15 \%$.

The brain of each sacrificed mouse was surgically isolated under anesthesia and homogenized with $0.2 \mathrm{~mL}$ of $1.15 \%$ $\mathrm{KCl}$. The homogenate was thoroughly mixed with $0.3 \mathrm{~mL}$ of HPLC in the mobile phase, and was centrifuged at 10,000 rpm for $30 \mathrm{~min}$ (Spectrafuge, USA). The supernatant was then separated, and HPLC analysis was performed. All the data were obtained in triplicate $(n=3)$.

\section{Statistical analysis}

One-way analyses of variance (ANOVA) was performed on the data as mean \pm SD to assess the size, polydispersity index, zeta potential, and in vitro and in vivo release (where, $\mathrm{n}=3$ ), and $P<0.05$ was considered significant. However, the anticonvulsant data was expressed as mean \pm SEM, and the significance of differences amongst the groups were determined using Tukey's post hoc test, using a one-way ANOVA.
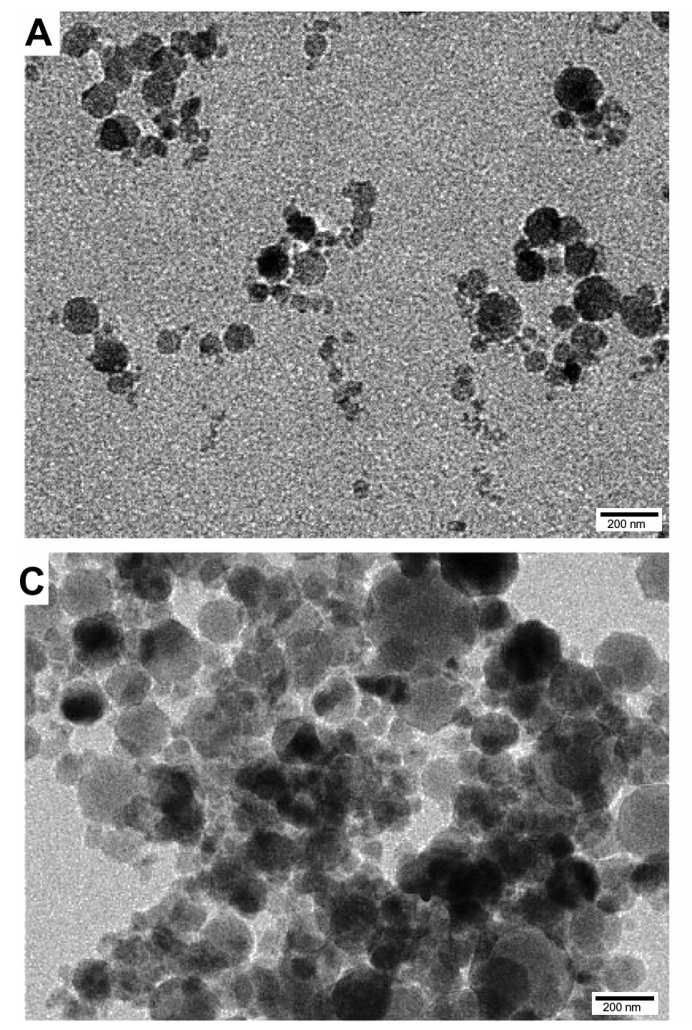

\section{Results and discussion}

All nanoparticle formulations were prepared by use of a solvent diffusion method, ${ }^{47}$ which provided a high entrapment efficiency at $83.0 \% \pm 3.8 \%$ for the drug. The placebo nanoparticles were an average size of $159.3 \pm 6.1 \mathrm{~nm}$; $\beta$-carotene-loaded nanoparticles were an average size of $169.8 \pm 4.8 \mathrm{~nm}$; while P-80-BCNP were an average size of $176.3 \pm 3.2 \mathrm{~nm}$. The nanoparticles were stored in reserve at $-4.0^{\circ} \mathrm{C} \pm 2.0^{\circ} \mathrm{C}$. The average size following 5 months of storage was determined to be approximately $187.4 \pm 3.8 \mathrm{~nm}$ for P-80-BCNP.

In general, particle aggregation is less likely to occur for charged particles (high \pm zeta potential) due to electric repulsion. Lower \pm zeta potential facilitates aggregation. Zeta potential of placebo nanoparticles was $-20 \pm 0.8 \mathrm{mV}$, which decreased to $-18 \pm 0.4 \mathrm{mV}$ for $\beta$-carotene-loaded nanoparticles making nanoparticles denser (Figure 2B). The zeta potential of P-80-BCNP was further decreased to $-16 \pm 0.3 \mathrm{mV}$ making it denser (Figure 2C and D). No appreciable changes were observed in the zeta potential after 5 months of storage at $-4.0^{\circ} \mathrm{C} \pm 2.0^{\circ} \mathrm{C}$. The polydispersity index shows the distribution measure of nanoparticles. A polydispersity index greater than 0.5 indicates aggregation
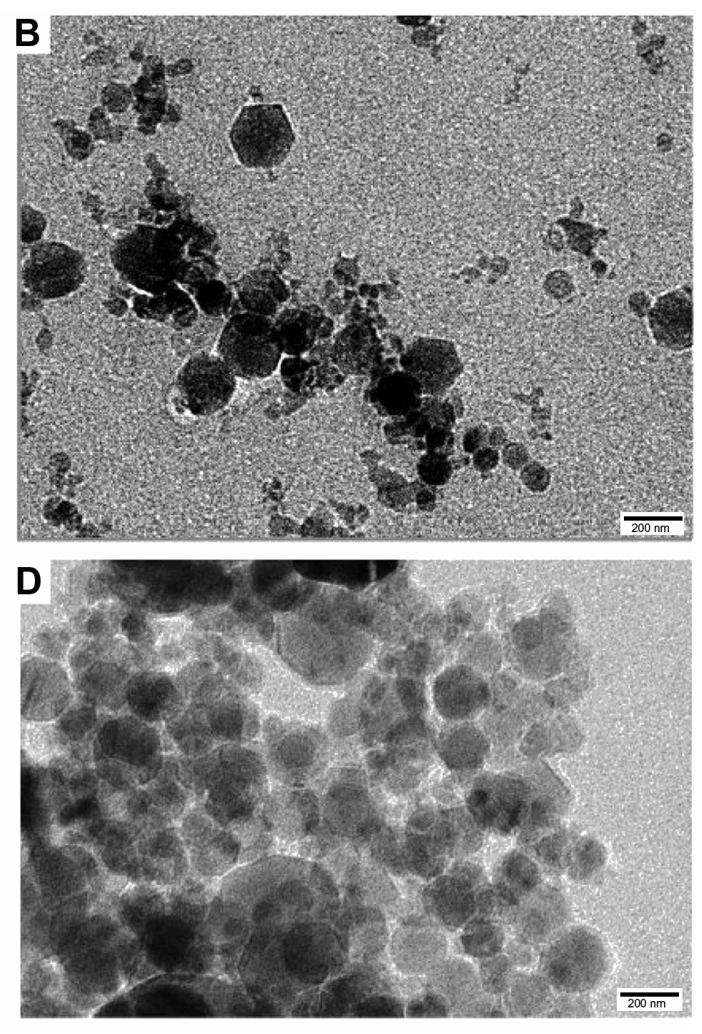

Figure 2 Transmission electron microscopic images. (A) Placebo nanoparticles; (B) Polymeric nanoparticles containing BCNP at a dose equivalent to 2 mg/kg body weight; (C) P-80-BCNP dose equivalent to $2 \mathrm{mg} / \mathrm{kg}$ body weight; (D) P-80-BCNP nanoparticles after 5 months.

Abbreviations: BCNP, $\beta$-carotene nanoparticles; P-80-BCNP, polysorbate-80-coated $\beta$-carotene. 
of particles; however, as the polydispersity index increased, it remained less than 0.5 after drug loading and polysorbate- 80 coating, which confirms no appreciable aggregation. It consistently remained constant after 5 months of storage. As reported, P-80-BCNP crossed the blood-brain barrier through endocytosis via adsorption of apolipoprotein $\mathrm{E}$ on its surface. The nanoparticles mimic low-density lipoprotein particles, allowing for an interaction with low-density lipoprotein receptors at the brain microvessel endothelial cells for bypass. ${ }^{39}$

The TEM images of the placebo nanoparticles (Figure 2A), $\beta$-carotene-loaded nanoparticles (Figure 2B), P-80-BCNP (Figure 2C), and over 5 months stored nanoformulations (Figure 2D) confirmed the shape, size, and storage stability of all the formulation versions used in this study. In addition, the morphological observations confirmed their spherical shape.

$\mathrm{X}$-ray diffraction studies revealed the amorphous natures of PVA and PLGA polymeric constituents, while $\beta$-carotene was determined to be in a crystalline form (Figure 3 ). The graphical comparison of nanoparticles with PVA and PLGA illustrate the idea of $\beta$-carotene dispersion inside the nanoparticles. In nanoparticle diffraction studies, no crystalline diffractions were observed, which led to the proposal of an amorphous nature of $\beta$-carotene constituent of polymeric nanoparticles. DSC is a thermal analytical technique that reveals the physical (crystalline/amorphous) nature and the possible interactions between different compounds of

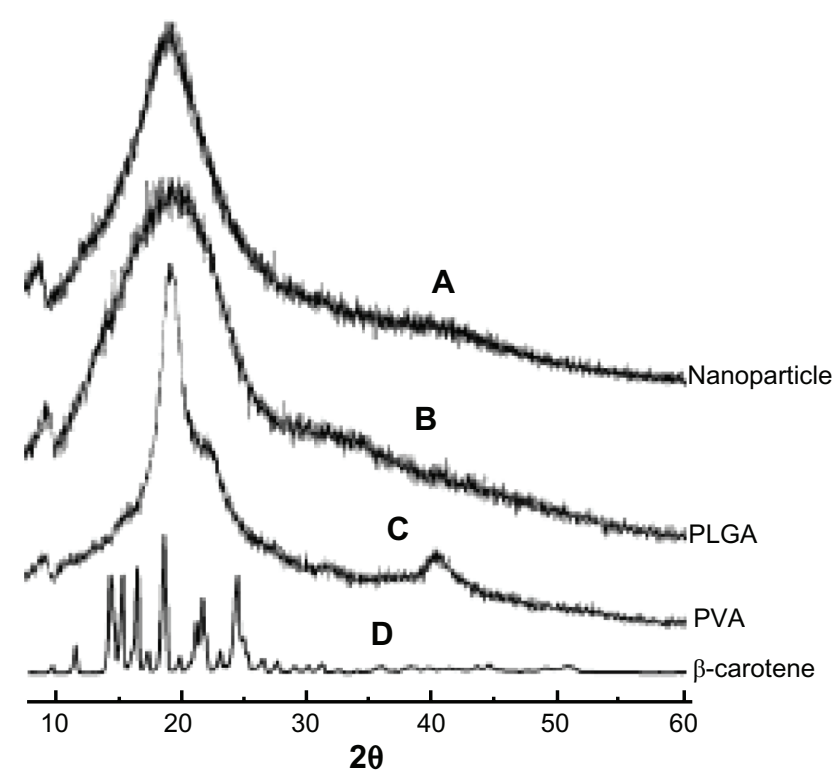

Figure 3 X-ray diffraction pattern. (A) $\beta$-carotene; (B) Polyvinyl alcohol; (C) poly(D,L-lactide-co-glycolide); (D) $\beta$-carotene nanoparticles. a mixture. The DSC studies revealed that both PVA and PLGA were amorphous at $\operatorname{Tg} 29^{\circ} \mathrm{C}$ (Figure $4 \mathrm{~A}$ ) and $44^{\circ} \mathrm{C}$ (Figure 4B), respectively. Conversely. free $\beta$-carotene was crystalline in nature with an exothermic peak at $\mathrm{Tg} 181^{\circ} \mathrm{C}$ (Figure. 4C). In the prepared formulation, very feeble and short peaks of PVA and PLGA polymers were found at $\mathrm{Tg}$ $27^{\circ} \mathrm{C}$ and $\mathrm{Tg} 39^{\circ} \mathrm{C}$, respectively, without demonstrating any peak for $\beta$-carotene, thus confirming its amorphous state in prepared nanoparticles. The interaction of PVA and PLGA polymers with $\beta$-carotene was found to be negligible as their glass transition temperatures were found to be at $27^{\circ} \mathrm{C}$ and $39^{\circ} \mathrm{C}$, respectively, indicating the level of the mentioned interactions (Figure 4D).

In the MES model, the duration of tonic hind limb extension (THLE duration) was used for biological study. In comparison to the normal control $(15.8 \pm 1.49$ seconds $)$, THLE duration of $\mathrm{BC}(200 \mathrm{mg} / \mathrm{kg})$ at $8.60 \pm 1.33 \mathrm{sec}(P<0.01)$; $\mathrm{BCNP}(\mathrm{BC}, 2 \mathrm{mg} / \mathrm{kg})$ at $9.30 \pm 0.86 \mathrm{sec}(P<0.05)$; and $\mathrm{P}-80-$ $\mathrm{BCNP}(\mathrm{BC}, 2 \mathrm{mg} / \mathrm{kg})$ at $2.10 \pm 1.16 \mathrm{sec}(P<0.001)$ were found to be significant. In comparison to the placebo control group, THLE duration of BCNP (BC, $2 \mathrm{mg} / \mathrm{kg}, P<0.01$ ) and $\mathrm{P}-80$-BCNP (BC, $2 \mathrm{mg} / \mathrm{kg}, P<0.001)$ were also determined to be significant. The THLE duration of BC $(2 \mathrm{mg} / \mathrm{kg})$ at $15.36 \pm 1.26$ seconds and placebo at $16.50 \pm 1.43$ seconds were found to be nonsignificant as there was no appreciable change. THLE duration of BCNP (BC, $2 \mathrm{mg} / \mathrm{kg}, P<0.05)$ and P-80-BCNP (BC, $2.0 \mathrm{mg} / \mathrm{kg}, P<0.001$ ) was determined to be very significant as compared to $\mathrm{BC}(2.0 \mathrm{mg} / \mathrm{kg})$. According to these findings, nonnanoformulated $\beta$-carotene at a dose level of $200 \mathrm{mg} / \mathrm{kg}$ was effective in reducing THLE duration, whereas the results of $2.0 \mathrm{mg} / \mathrm{kg}$ of the same group showed effects similar to normal control. This is indicative of the fact that $2.0 \mathrm{mg} / \mathrm{kg}$ is an ineffective dose. In the nanoformulated form, a dose level of $2.0 \mathrm{mg} / \mathrm{kg}$ showed an effective decrease in THLE duration, and the effect was further potentiated via polysorbate- 80 coating, which established the successful targeting of $2.0 \mathrm{mg} / \mathrm{kg}$ nanoformulated $\beta$-carotene to the brain.

In the PTZ study, the GTCS duration in PTZ control ( $8.20 \pm 0.80$ seconds) was found to be significant $(P<0.001)$ in comparison to the normal control $(0.0 \pm 0.0$ seconds $)$. In comparison to the PTZ control, GTCS duration of PTZ $+\mathrm{BC}$ $(200 \mathrm{mg} / \mathrm{kg})$ at $5.28 \pm 0.35$ seconds $(P<0.01)$; PTZ + BCNP $(\mathrm{BC}, 2.0 \mathrm{mg} / \mathrm{kg})$ at $2.90 \pm 0.98$ seconds $(P<0.001)$; and PTZ + P-80-BCNP (BC, $2.0 \mathrm{mg} / \mathrm{kg})$ at $1.20 \pm 0.20$ seconds $(P<0.001)$ were found to be significant. In comparison to the PTZ-control group, GTCS duration of PTZ + BCNP (BC, $2.0 \mathrm{mg} / \mathrm{kg}$ ) and PTZ + P-80-BCNP (BC $2.0 \mathrm{mg} / \mathrm{kg}$ ) were also 

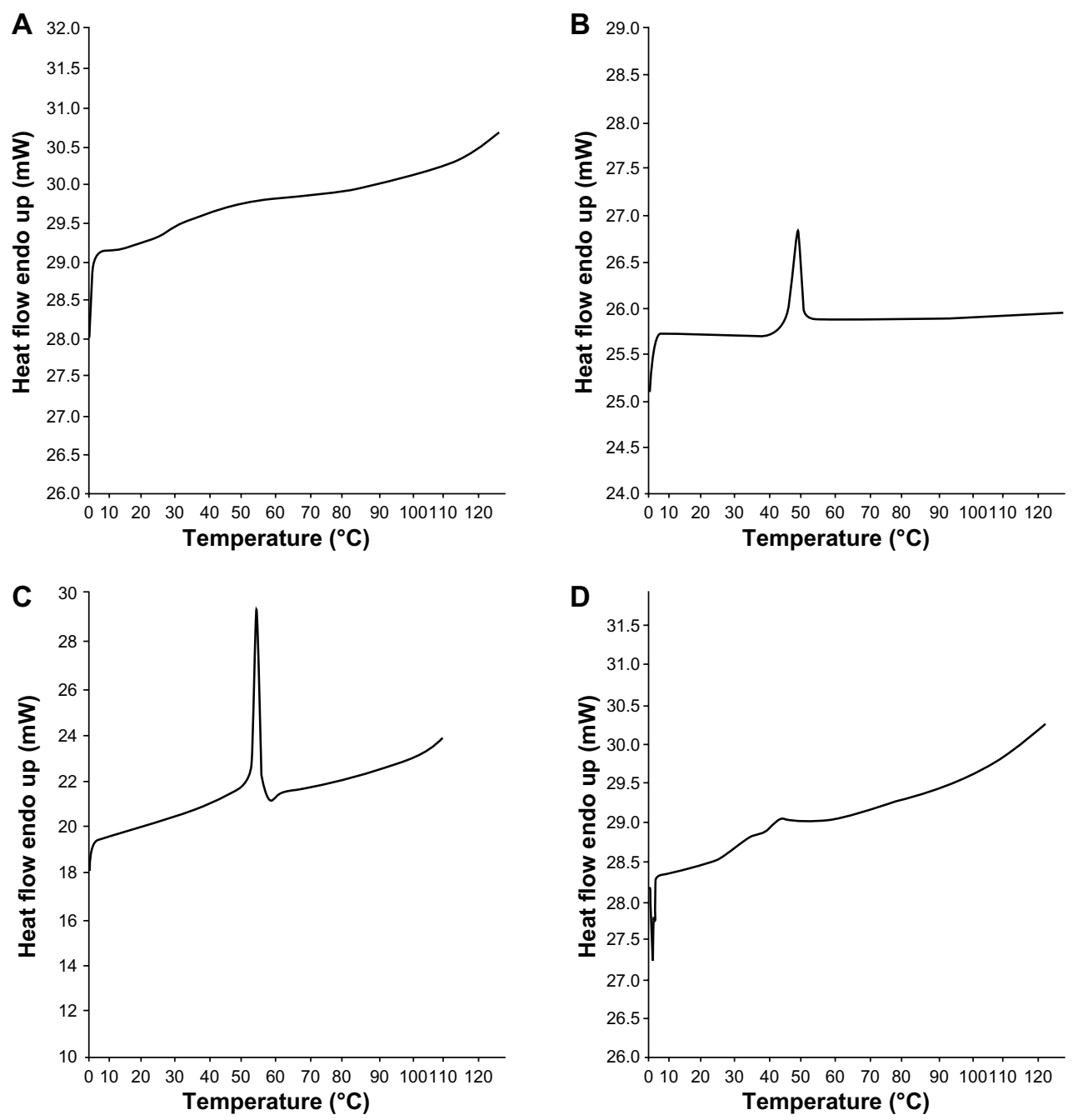

Figure 4 Differential scanning calorimetry studies. (A) Polyvinyl alcohol; (B) poly(D,L-lactide-co-glycolide); (C) $\beta$-carotene; (D) $\beta$-carotene nanoparticles.

found to be significant $(P<0.001)$. The GTCS duration of $\mathrm{PTZ}+\mathrm{BC}(2.0 \mathrm{mg} / \mathrm{kg})$ at $8.12 \pm 0.32$ seconds and PTZ + placebo at $8.09 \pm 0.26$ seconds were found to be nonsignificant as there was no appreciable change. GTCS duration of $\mathrm{PTZ}+\mathrm{BCNP}$ (BC, $2.0 \mathrm{mg} / \mathrm{kg})$ and PTZ + P-80-BCNP (BC, $2.0 \mathrm{mg} / \mathrm{kg})$ was found to be very significant $(P<0.001)$ as compared to PTZ + BC (2.0 mg/kg).

The GTCS latency of PTZ control was found to be highly significant $(P<0.001)$ at $120.10 \pm 4.5$ seconds compared to normal control. In comparison to the PTZ control, GTCS latency of PTZ + BC $(200 \mathrm{mg} / \mathrm{kg})$ at $167.00 \pm 5.2$ seconds $(P<0.01)$; PTZ + BCNP $(\mathrm{BC}$, $2.0 \mathrm{mg} / \mathrm{kg})$ at $191.00 \pm 9.80$ seconds $(P<0.001)$; and $\mathrm{PTZ}+\mathrm{P}-80-\mathrm{BCNP}(\mathrm{BC}, 2.0 \mathrm{mg} / \mathrm{kg})$ at $231.00 \pm 16.3$ seconds $(P<0.01)$ were all found to be significant. In comparison to the PTZ control group, GTCS latency of PTZ + BCNP (BC, $2.0 \mathrm{mg} / \mathrm{kg}, P<0.001)$ and PTZ + P-80-BCNP (BC $2.0 \mathrm{mg} / \mathrm{kg}$,
$P<0.001)$ were also found to be significant. The GTCS latency of PTZ $+\mathrm{BC}(2.0 \mathrm{mg} / \mathrm{kg})$ at $118.0 \pm 6.5$ seconds and $\mathrm{PTZ}+$ placebo control at $120.30 \pm 7.4$ seconds were found to be nonsignificant compared to PTZ-control, which exhibited no appreciable change in GTCS latency. The GTCS latency of PTZ + BCNP (BC, $2.0 \mathrm{mg} / \mathrm{kg}$ ) and PTZ + P-80-BCNP (BC, $2 \mathrm{mg} / \mathrm{kg})$ were found to be very significant $(P<0.001)$ as compared to PTZ + BC (2.0 mg/kg).

As the decrease in GTCS duration and increase in GTCS latency were observed in comparison to both PTZ normal and placebo control, it was concluded that normal nonnanoformulated effective dose of $\beta$-carotene was $200 \mathrm{mg} / \mathrm{kg}$. A dose of $2.0 \mathrm{mg} / \mathrm{kg}$ is effective only in a nanoformulation dosage form. A decrease in GTCS duration and an increase in GTCS latency of both BCNP and P-80-BCNP demonstrates an effectiveness of $\beta$-carotene at a $2.0 \mathrm{mg} / \mathrm{kg}$ concentration in nanoparticle form (Figure 5). 

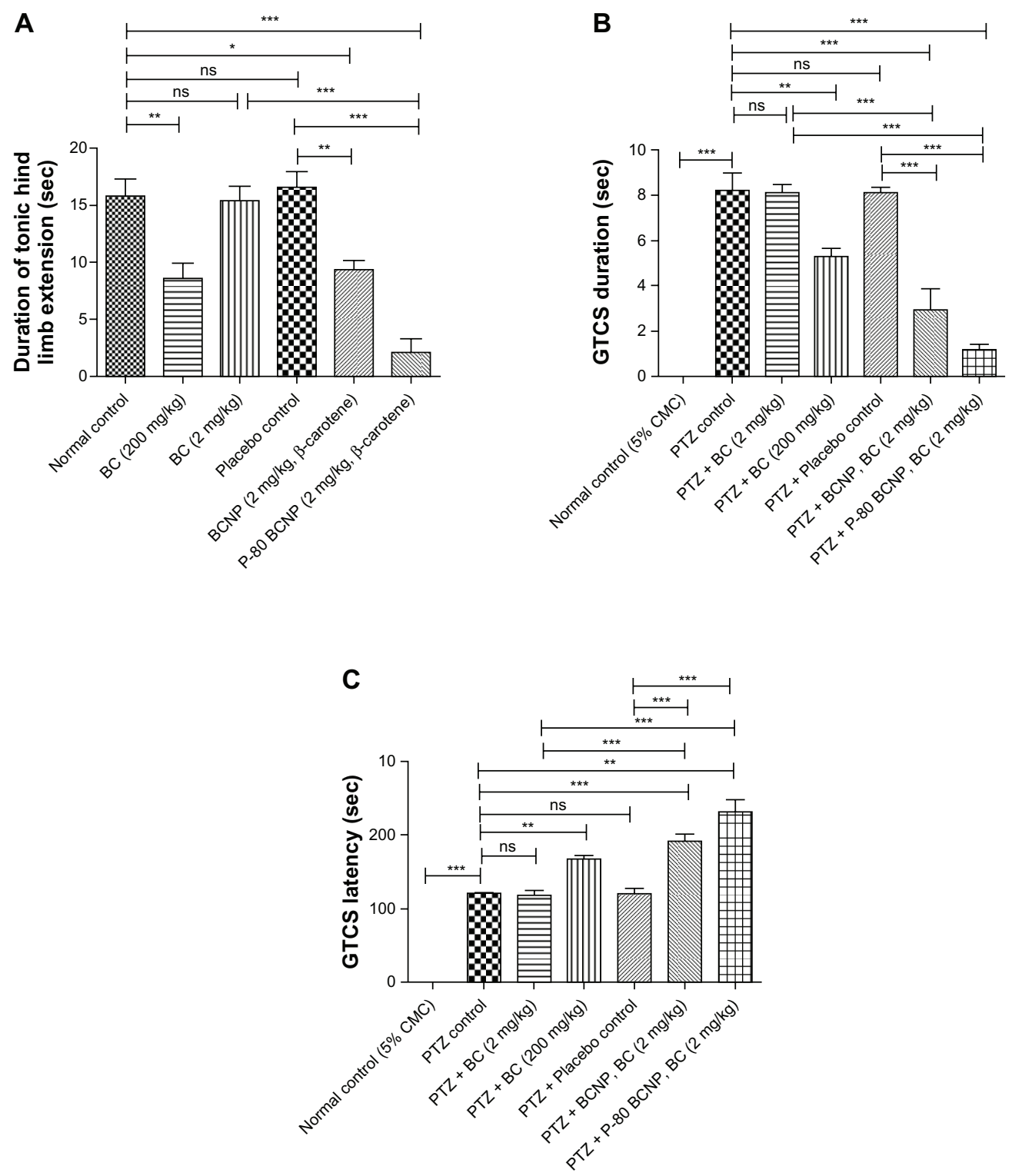

Figure 5 Anticonvulsant activity. (A) Maximal electroshock seizure test; duration of hind limb muscle extension in normal control, placebo control, $\beta$-carotene 2 mg/kg, $\beta$-carotene $200 \mathrm{mg} / \mathrm{kg}, \mathrm{BCNP}$ (2.0 mg/kg $\beta$-carotene), and P-80-BCNP (2.0 mg/kg $\beta$-carotene) are shown in the graph. Response of dosage forms were compared to placebo control. (B) General tonic-clonic seizure latency test. Latency duration was compared in normal control, PTZ Control, PTZ + BC (2.0 mg/kg), PTZ + BC (200 mg/kg), PTZ + placebo control, PTZ + BCNP (BC, $2.0 \mathrm{mg} / \mathrm{kg})$, and PTZ + P-80-BCNP BC $(2.0 \mathrm{mg} / \mathrm{kg})$ are shown in the graph. (C) General tonic-clonic seizure duration in normal control, PTZ control, PTZ + BC (2.0 mg/kg), PTZ + BC (200 mg/kg), PTZ + placebo control, PTZ + BCNP (BC, $2.0 \mathrm{mg} / \mathrm{kg})$, PTZ + P-80-BCNP, (BC, $2.0 \mathrm{mg} / \mathrm{kg})$. The study was done on albino mice model of six animals in each group $(n=6)$. Comparisons among the groups are shown by arrows as indicated in the graph.

Notes: Results are expressed as mean \pm SEM. Statistical analysis was performed using one-way ANOVAs with Tukey's post hoc test. Significance compared with epileptic mice are $* P<0.05, * * P<0.001, * * * P<0.001$.

Abbreviations: BCNP, $\beta$-carotene nanoparticles; PTZ, pentylenetetrazole; BC, $\beta$-carotene; P-80-BCNP, polysorbate-80-nanoparticles; ANOVA, analysis of variance; ns, nonsignificant.

\section{In vitro release kinetics}

The release kinetics of $\beta$-carotene-loaded PLGA nanoparticles showed an initial burst release followed by a sustained release, which continued for seven days (Figure 6). In vitro release studies are required to predict the release pattern of a drug from the encapsulating material as it affects a drug's bioavailability. ${ }^{48}$ Hence, knowing the quantity of residually encapsulated drug in in vitro release is crucial for drug delivery regime maintenance. The in vitro release profiles of $\beta$-carotene from PLGA nanoparticles are presented in Figure 6, which shows a typical biphasic pattern. Initially, a burst release occurred during the first 12 hours with 


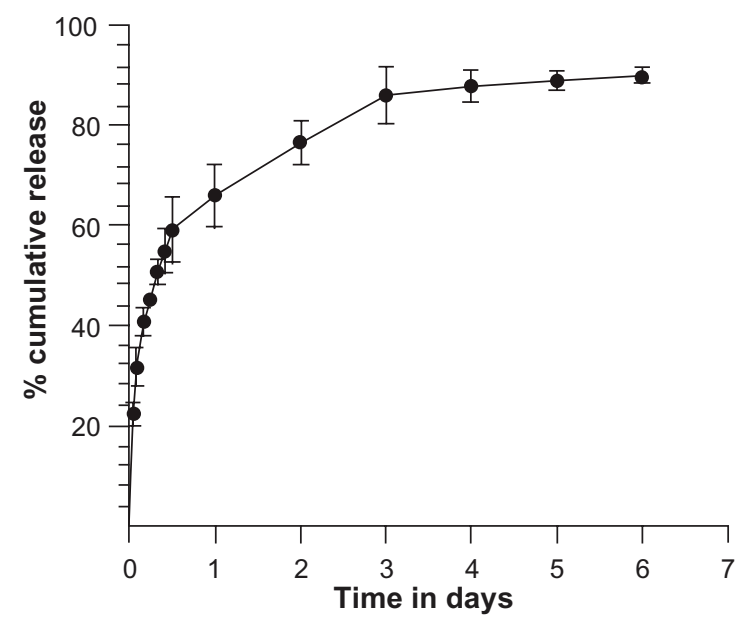

Figure 6 In vitro release study of BCNP for one week. Note: Determinations were done as mean \pm SD from three samples $(n=3)$.

$56.0 \% \pm 6.2 \%$ of $\beta$-carotene release from PLGA nanoparticles. Following this, a sustained drug release from BCNP was observed from $58.0 \% \pm 7.7 \%$ to $88.6 \% \pm 1.3 \%$ after 6 days. The sustained release profile of $\beta$-carotene from nanoparticles was consistent with the Higuchi diffusion equation $\left(r^{2}=0.95\right)$, which is defined as follows: ${ }^{49}$

$$
Q=2 C_{0}(D t \mid x)^{1 / 2}
$$

where $Q$ is the cumulative amount of drug released per unit of surface area, $C_{0}$ is the initial drug loading, $D$ is the diffusion coefficient, $t$ is the time after commencement of diffusion, and $x$ is the constant of the equation.

The drug release from the PLGA polymer displayed multiple release phases including initial burst release, lag phase, and zero order release..$^{50}$ The initial burst release is regulated by diffusion through the surface and poreassociated release of the drug. The lag phase and zero order releases are controlled by polymer erosion combined with the diffusion quotient. ${ }^{51}$ The sustained release of the drug in a delivery system is an important property closely related with therapeutics-linked pharmacokinetics and contributes to the efficacy of the drug. ${ }^{52}$

\section{Brain release of $\beta$-carotene}

The mean concentrations of free drug and nanoformulations in brain tissue homogenate after intraperitoneal administration are illustrated (Figure 7). The relevant pharmacokinetic parameters including $\mathrm{C}_{\max }$ and $\mathrm{T}_{\max }$ are listed in the graph (Figure 7). The concentrations $(\mathrm{ng} / \mathrm{mL})$ of $\beta$-carotene in brain tissue homogenate were plotted against time to generate

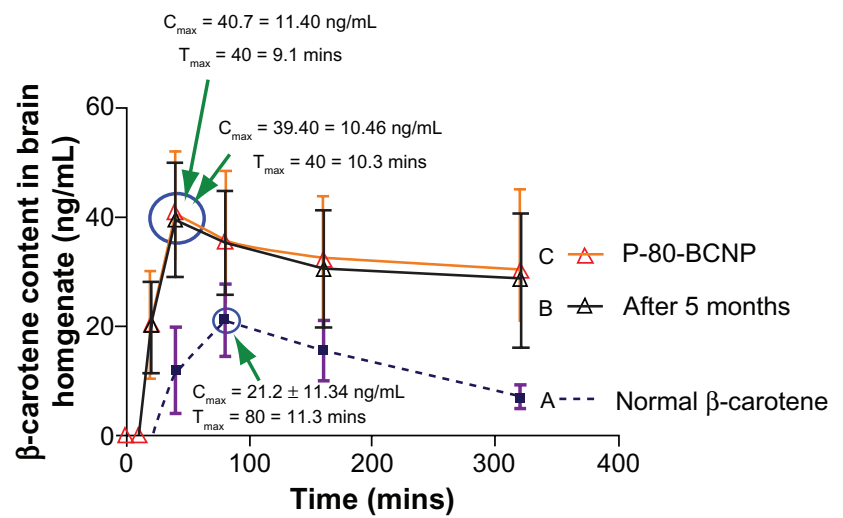

Figure 7 Brain release of $\beta$-carotene. (A) In BCNP formulation; (B) In P-80-BCNP formulation; (C) In P-80-BCNP formulation after 5 months storage. Note: Data is shown in mean \pm SD from three samples $(n=3)$.

Abbreviations: BCNP, $\beta$-carotene nanoparticles; P-80-BCNP, polysorbate-80 $\beta$-carotene nanoparticles.

the in vivo release study of P-80-BCNP. From the graph obtained by plotting concentration $(\mathrm{ng} / \mathrm{mL})$ against time, it was observed that the coated nanoformulation showed sustained release over a long period. Free drug $\beta$-carotene was noticed in very low brain concentration with a $\mathrm{C}_{\max }$ of $21.2 \pm 11.80 \mathrm{ng} / \mathrm{mL}$ and $\mathrm{T}_{\text {max }}$ of $80 \pm 11.3$ minutes, which was followed by a rapid concentration decline in brain tissue homogenate over time. A relatively slow increase and sustained brain concentration of $\beta$-carotene was observed with the nanoformulation having $\mathrm{C}_{\max }$ of $40.7 \pm 11.40 \mathrm{ng} / \mathrm{mL}$ with significantly delayed $\mathrm{T}_{\max }$ of $40 \pm 9.1$ minutes. Brain release pattern was not affected much by storing the nanoformulation for 5 months, as it showed a $\mathrm{C}_{\max }$ of $39.40 \pm 10.46 \mathrm{ng} / \mathrm{mL}$ and a $\mathrm{T}_{\max }$ of $40 \pm 10.3$ minutes.

\section{Possible mechanism of $\beta$-carotene anticonvulsant action}

$\beta$-Carotene is a chain-breaking antioxidant, and a similar structural mechanism has been reported earlier ${ }^{53,54}$ (ie, it is able to impede oxidizing radicals directly, preventing the chain propagation step during lipid auto-oxidation). It reacts with alkoxy radicals, lipid peroxy radicals, and alkyl radicals derived from polyunsaturated fatty acids oxidation (Figure 8A). ${ }^{55}$ The reaction between $\beta$-carotene and lipid free radicals occurs at the membrane water interphase, where $\beta$-carotene is believed to donate a hydrogen ion to lipid radicals with oxyl radical (BOH) generation. ${ }^{55}$ In addition, it also acts as a chemical scavenger for oxygen radicals, especially for singlet oxygen (via irreversible oxidation), and acts as a physical deactivator of singlet oxygen by charge transfer mechanism (Figure 8B). ${ }^{15,54}$ 


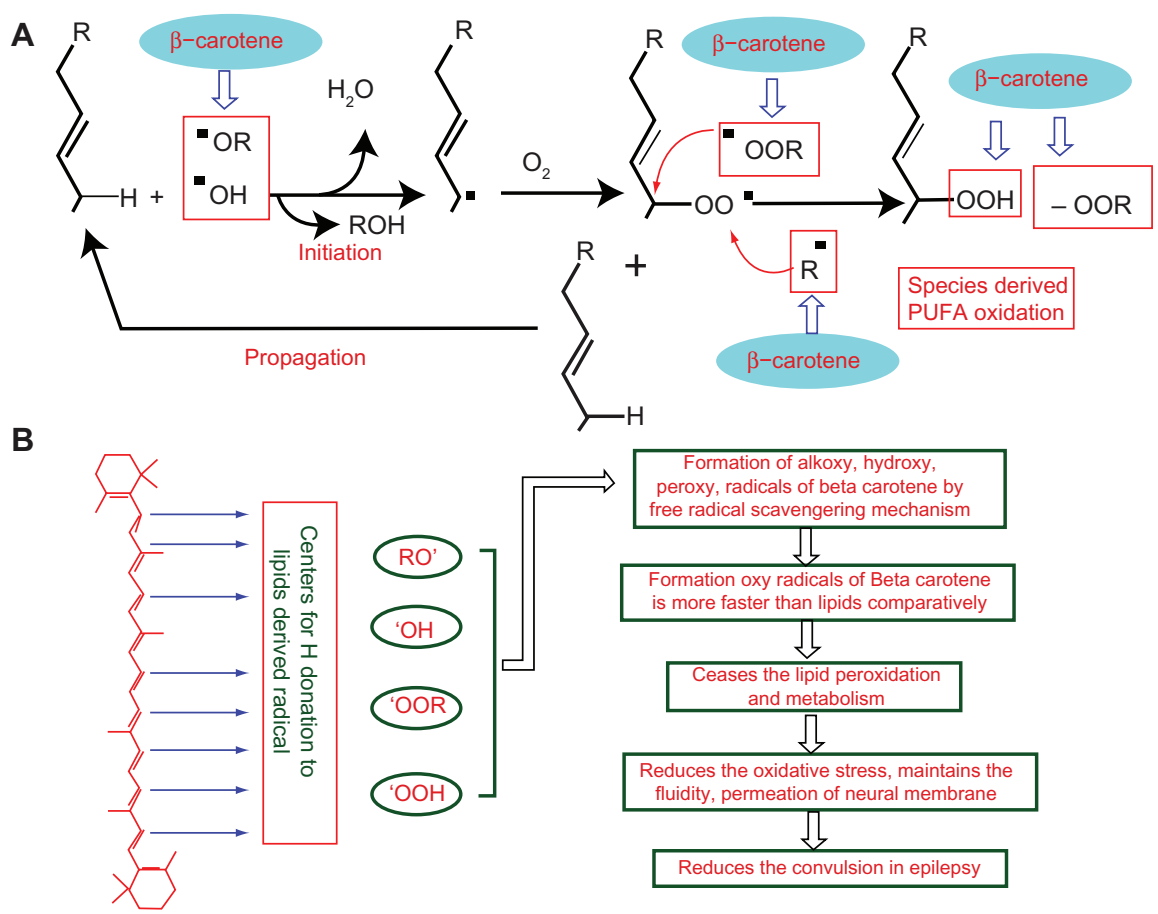

Figure 8 Mechanism of free radical formation of PUFA and possible mechanism of $\beta$-carotene bio-action. (A) Mechanism of free radical formation of PUFA. Free radicals are formed via donation of hydrogen to alkoxy or hydroxy free radical. Free radical of PUFA further forms peroxides. Possible site of $\beta$-carotene action as free radical scavenger. (B) Possible mechanism of $\beta$-carotene bio-action.

Abbreviation: PUFA, polyunsaturated fatty acids.

\section{Conclusion}

$\beta$-Carotene containing polysorbate-80-coated polymeric nanoparticles were prepared by a solvent diffusion method and were well characterized for shape, average size, and zeta potential. The coated nanoformulation was stable for a longer period without significant deformities in size and shape, including their stable and unaltered zeta potential charge for approximately 5 months. The nanoformulation was delivered at a $2.0 \mathrm{mg} / \mathrm{kg}$ dose level through an intraperitoneal route, and sustained release accomplished the desired bioavailability demand which was confirmed as the slowdown dose requirement for induced convulsions in experimental animal models. Thus, polysorbate- 80 -coated nanoparticles potentiated the antioxidant biological action of $\beta$-carotene which is otherwise unfavored by conventional delivery systems. The dose, activity levels, and delivery mode of this formulation may herald a novel therapeutic approach for epilepsy in the near future.

\section{Acknowledgments}

The authors are grateful for laboratory and Animal House facilities at Hamdard University, New Delhi. Mohammad Yusuf is thankful to UGC, New Delhi for grant of a fellowship.

\section{Disclosure}

The authors report no conflicts of interest in this work.

\section{References}

1. World Health Organization. Fact Sheet No 165. Epilepsy: Epidemiology, Etiology and Prognosis. Geneva: World Health Organization; 2001.

2. Patel M. Mitochondrial dysfunction and oxidative stress: cause and consequence of epileptic seizures. Free Radic Bio Med. 2004;37(12): 1951-1962.

3. Levine SA, Kidd PM. Antioxidant adaptation: a unified disease theory. J Orthomol Med. 1985;14(1):19-38.

4. Stadtman ER. Protein oxidation in aging and age-related diseases. Ann NY Acad Sci. 2001;928:22-38.

5. Gajewska E, Bernat P, Długoński J, Skłodowska M. Effect of nickel on membrane integrity, lipid peroxidation and fatty acid composition in wheat seedlings. Journal of Agronomy and Crop Sciences. 2012;198(4): 286-294.

6. Chang RC, Hudson PM, Wilson BC, Liu B, Abel H, Hong JS. High concentrations of extracellular potassium enhance bacterial endotoxin lipopolysaccharide-induced neurotoxicity in glial neuron mixed cultures. Neuroscience. 2000;97(4):757-764.

7. Hyrc K, Handran SD, Rothman SM, Goldberg MP. Ionized intracellular calcium concentration predicts excitotoxic neuronal death: observations with low-affinity fluorescent calcium indicators. $J$ Neurosci. September 1, 1997;17(17):6669-6677.

8. Kuppusamy P, Zweier JL. Characterization of free radical generation by xanthine oxidase. Evidence for hydroxyl radical generation. $J$ Biol Chem. June 15, 1989;264(17):9880-9884.

9. Abramov AY, Scorziello A, Duchen MR. Three distinct mechanisms generate oxygen free radicals in neurons and contribute to cell death during anoxia and reoxygenation. $J$ Neurosci. 2007;27(5): $1129-1138$.

10. Brown GC, Borutaite V. Nitric oxide, mitochondria, and cell death. IUBMB Life. 2001;52(3-5):189-195.

11. Graf E, Mahoney JR, Bryant RG, Eaton JW. Iron-catalyzed hydroxyl radical formation. Stringent requirement for free iron coordination site. J Biol Chem. 1984;259(6):3620-3624. 
12. Lehninger AL. The neuronal membrane. Proc Natl Acad Sci U S A. 1968;60(4):1069-1080.

13. Erakovic V, Zupan G, Varljen J, Simonic A. Pentylenetetrazolinduced seizures and kindling: changes in free fatty acids, superoxide dismutase, and glutathione peroxidase activity. Neurochem Int. 2003; 42(2):173-178.

14. Ashrafi MR, Shams S, Nouri M, et al. A probable causative factor for an old problem: selenium and glutathione peroxidase appear to play important roles in epilepsy pathogenesis. Epilepsia. 2007; 48(9):1750-1755.

15. Sharma MK, Buettner GR. Interaction of vitamin $C$ and vitamin $E$ during free radical stress in plasma: an ESR study. Free Radic Biol Med. 1993;14(6):649-653.

16. Winyard PG, Moody CJ, Jacob C. Oxidative activation of antioxidant defence. Trends Biochem Sci. 2005;30(8):453-461.

17. Dal Pizzol F, Klamt F, Vianna M, et al. Lipid peroxidation in hippocampus early and late after status epilepticus induced by pilocarpine or kainic acid in Wistar rats. Neurosci Lett. 2000;291(3): $179-182$.

18. Kabuto H, Yokoi I, Ogawa N. Melatonin inhibits iron-induced epileptic discharges in rats by suppressing peroxidation. Epilepsia. 1998;39(3): 237-243.

19. Rola R, Swiader M, Czuczwar S. Electroconvulsions elevate the levels of lipid peroxidation products in mice. Pol J Pharmacol. 2002;54(5):521-524.

20. Nieoczym D, Albera E, Kankofer M, Wlaź P. Maximal electroshock induces changes in some markers of oxidative stress in mice. J Neural Transm. 2008;115(1):19-25.

21. Frantseva MV, Perez Velazquez JL, Tsoraklidis G, et al. Oxidative stress is involved in seizure-induced neurodegeneration in the kindling model of epilepsy. Neuroscience. 2000;97(3):431-435.

22. Rauca C, Wiswedel I, Zerbe R, Keilhoff G, Krug M. The role of superoxide dismutase and alpha-tocopherol in the development of seizures and kindling induced by pentylenetetrazol - influence of the radical scavenger alpha-phenyl-N-tert-butyl nitrone. Brain Res. 2004; 1009(1-2):203-212.

23. Ekonomou A, Angelatou F. Upregulation of NMDA Receptors in hippocampus and cortex in the pentylenetetrazol-induced "kindling" model of epilepsy. Neurochem Res. 1999;24(12):1515-1522.

24. Uma Devi P, Pillai KK, Vohora D. Modulation of pentylenetetrazoleinduced seizures and oxidative stress parameters by sodium valproate in the absence and presence of $\mathrm{N}$-acetylcysteine. Fundam Clin Pharmacol. 2006;20(3):247-253.

25. Krinsky NI. Antioxidant functions of carotenoids. Free Radic Biol Med. 1989;7(6):617-635.

26. Palace VP, Khaper N, Qin Q, Singal PK. Antioxidant potentials of vitamin A and carotenoids and their relevance to heart disease. Free Radic Biol Med. 1999;26(5-6):746-761.

27. Sayyah M, Yousefi-Pour M, Narenjkar J. Anti-epileptogenic effect of beta-carotene and vitamin A in pentylenetetrazole-kindling model of epilepsy in mice. Epilepsy Res. 2005;63(1):11-16.

28. Bitterman N, Melamed Y, Ben-Amotz A. Beta-carotene and CNS oxygen toxicity in rats. J Appl Physiol. 1994;76(3):1073-1076.

29. Obulesu M, Dowlathabad MR, Bramhachari PV. Carotenoids and Alzheimer's disease: an insight into therapeutic role of retinoids in animal models. Neurochem Int. 2011;59(5):535-541.

30. Deming DM, Erdman JW Jr. Mammalian carotenoid absorption and metabolism. Pure Appl Chem. 1999;71(12):2213-2223.

31. Auweter H, Haberkorn H, Heckmann W, et al. Supramolecular structure of precipitated nanosize beta-carotene particles. Angew Chem Int Ed Engl. 1999;38(15):2188-2191.

32. Horn D. Preparation and characterization of microdisperse bioavailable carotenoid hydrosols. Die Angewandte Makromolekular Chemie. 1989; 166(1):139-153.

33. Fessi H, Puisieux F, Devissaguet JP, Ammoury N, Benita S. Nanocapsule formation by interfacial polymer deposition following solvent displacement. Int J Pharm. 1989;55(1):R1-R4.
34. Grolier P, Azais-Braesco V, Zelmire L, Fessi H. Incorporation of carotenoids in aqueous systems: uptake by cultured rat hepatocytes. Biochim Biophys Acta. 1992;1111(1):135-138.

35. Szczepanowicz K, Hoel HJ, Szyk-Warszynska L, et al. Formation of biocompatible nanocapsules with emulsion core and pegylated shell by polyelectrolyte multilayer adsorption. Langmuir. 2010;26(15): 12592-12597.

36. Zhu Z, Margulis-Goshen K, Magdassi S, Talmon Y, Macosko CW. Polyelectrolyte stabilized drug nanoparticles via flash nanoprecipitation: a model study with beta-carotene. J Pharm Sci. 2010;99(10): 4295-4306.

37. Costantino L, Gandolfi F, Tosi G, Rivasi F, Vandelli MA, Forni F. Peptide-derivatized biodegradable nanoparticles able to cross the blood-brain barrier. J Control Release. 2005;108(1):84-96.

38. Dechy-Cabaret O, Martin-Vaca B, Bourissou D. Controlled ring-opening polymerization of lactide and glycolide. Chem Rev. 2004;104(12): 6147-6176.

39. Kreuter J. Influence of the surface properties on nanoparticle-mediated transport of drugs to the brain. J Nanosci Nanotechnol. 2004;4(5): 484-488.

40. Kim HR, Andrieux K, Gil S, et al. Translocation of poly(ethylene glycolco-hexadecyl) cyanoacrylate nanoparticles into rat brain endothelial cells: role of apolipoproteins in receptor-mediated endocytosis. Biomacromolecules. 2007;8(3):793-799.

41. Michaelis K, Hoffmann MM, Dreis S, et al. Covalent linkage of apolipoprotein e to albumin nanoparticles strongly enhances drug transport into the brain. J Pharmacol Exp Ther. 2006;317(3):1246-1253.

42. Petri B, Bootz A, Khalansky A, et al. Chemotherapy of brain tumour using doxorubicin bound to surfactant-coated poly(butyl cyanoacrylate) nanoparticles: revisiting the role of surfactants. J Control Release. 2007; 117(1):51-58.

43. Kreuter J, Hekmatara T, Dreis S, Vogel T, Gelperina S, Langer K. Covalent attachment of apolipoprotein A-I and apolipoprotein B-100 to albumin nanoparticles enables drug transport into the brain. $J$ Control Release. 2007;118(1):54-58.

44. Hung LC, Basri M, Tejo BA, et al. An improved method for the preparations of nanostructured lipid carriers containing heat-sensitive bioactives. Colloids Surf B Biointerfaces. 2011;87(1):180-186.

45. Cashin $\mathrm{CH}$, Jackson $\mathrm{H}$. An apparatus for testing anticonvulsant drugs by electroshock seizures in mice. J Pharm Pharmacol. 1962; 14(Suppl):44T-47T.

46. Dhir A. Pentylenetetrazol (PTZ) Kindling Model of Epilepsy. Curr Protoc Neurosci. 2012;DOI:10.1002/0471142301.ns0937s58. Epub January 1, 2012.

47. Horn D, Rieger J. Organic nanoparticles in the aqueous phase-theory, experiment, and use. Angew Chem Int Ed Engl. 2001;40(23):4330-4361.

48. Müller R. Colloidal Carriers for Controlled Drug Delivery and Targeting: Modification, Characterization, and In Vivo Distribution. Boca Raton: CRC Press; 1991:45-56.

49. Higuchi T. Mechanism of sustained-action medication. Theoretical analysis of rate of release of solid drugs dispersed in solid matrices. J Pharm Sci. 1963;52:1145-1149.

50. Zolnik BS, Burgess DJ. Effect of acidic pH on PLGA microsphere degradation and release. J Control Release. 2007;122(3):338-344.

51. Faisant N, Siepmann J, Benoit JP. PLGA-based microparticles: elucidation of mechanisms and a new, simple mathematical model quantifying drug release. Eur J Pharm Sci. 2002;15(4):355-366.

52. Zolnik BS, Leary PE, Burgess DJ. Elevated temperature accelerated release testing of PLGA microspheres. J Control Release. 2006;112(3): 293-300.

53. Serbinova EA, Packer L. Antioxidant properties of alpha-tocopherol and alpha-tocotrienol. Methods Enzymol. 1994;234:354-366.

54. Buettner GR. The pecking order of free radicals and antioxidants: lipid peroxidation, alpha-tocopherol, and ascorbate. Arch Biochem Biophys. 1993;300(2):535-543.

55. Kamal Eldin A, Appelqvist L. The chemistry and antioxidant properties of tocopherols and tocotrienols. Lipids. 1996;31(7):671-701. 


\section{Publish your work in this journal}

The International Journal of Nanomedicine is an international, peerreviewed journal focusing on the application of nanotechnology in diagnostics, therapeutics, and drug delivery systems throughout the biomedical field. This journal is indexed on PubMed Central, MedLine, CAS, SciSearch $\AA$, Current Contents ${ }^{\circledR} /$ Clinical Medicine,
Journal Citation Reports/Science Edition, EMBase, Scopus and the Elsevier Bibliographic databases. The manuscript management system is completely online and includes a very quick and fair peer-review system, which is all easy to use. Visit http://www.dovepress.com/ testimonials.php to read real quotes from published authors.

Submit your manuscript here: http://www.dovepress.com/international-journal-of-nanomedicine-journal 